\title{
Using protein-fatty acid complexes to improve vitamin D stability
}

\author{
Jannik Nedergaard Pedersen, ${ }^{*}$ Henriette Søster Frislev, ${ }^{*}$ Jan Skov Pedersen, $\dagger$ and Daniel E. Otzen ${ }^{*}{ }^{1}$ \\ *Interdisciplinary Nanoscience Center (iNANO), Department of Molecular Biology and Genetics, and \\ †Department of Chemistry and Interdisciplinary Nanoscience Center (iNANO), Aarhus University, Gustav Wieds Vej 14, \\ DK-8000 Aarhus C, Denmark
}

\section{ABSTRACT}

Liprotides are complexes between lipids and partially denatured proteins in which the protein forms a stabilizing shell around a fatty acid micelle core. We have previously shown that liprotides stabilize small aliphatic molecules such as retinal and tocopherol by sequestering these molecules in the fatty acid core. This opens up the use of liprotides to formulate food additives. Here, we expand our investigations to the large and bulky molecule vitamin $\mathrm{D}_{3}$ (vitD), motivated by the population-wide occurrence of vitD deficiency. We prepared liprotides using different proteins and fatty acids and evaluated their ability to protect vitD upon exposure to heating or intense UV light. Additionally, we determined the stability of liprotides toward $\mathrm{pH}$, $\mathrm{Ca}^{2+}$, and BSA. The best results were obtained with liprotides made from $\alpha$-lactalbumin and oleate. These liprotides were able to completely solubilize vitD, increase the stability toward UV light 9-fold, and increase the long-term stability at $37^{\circ} \mathrm{C}$ up to 1,000 -fold. Native $\alpha$-lactalbumin binds $\mathrm{Ca}^{2+}$, making $\mathrm{Ca}^{2+}$ potentially disruptive toward liprotides. However, liprotides prepared by incubation at $80^{\circ} \mathrm{C}$ were stable toward $\mathrm{Ca}^{2+}$, in contrast to those made at $20^{\circ} \mathrm{C}$. Nevertheless, the fatty acid binding protein BSA reduced the ability of both liprotides to protect vitD; the amount of vitD remianing after $20 \mathrm{~d}$ at $20^{\circ} \mathrm{C}$ decreased from $79 \pm 3 \%$ in the absence of BSA to $49 \pm 4$ and $23 \pm 3 \%$ in the presence of BSA for liprotides made at 80 and $20^{\circ} \mathrm{C}$, respectively. Both classes of liprotides were able to release their vitD content, as demonstrated by the transfer of vitD encapsulated in liprotides to phospholipid vesicles. Importantly, liprotides were not stable at $\mathrm{pH} 6$ and below, limiting the useful $\mathrm{pH}$ range of the liprotides to $>\mathrm{pH}$ 6. Our results indicate that vitD may be encapsulated and stabilized for enrichment of clear beverages at neutral $\mathrm{pH}$ to improve the intake and bioavailability of vitD.

\footnotetext{
Received April 21, 2016.

Accepted June 18, 2016.

${ }^{1}$ Corresponding author: dao@inano.au.dk
}

Key words: liprotide, vitamin D, stabilization, $\alpha$-lactalbumin, oleic acid

\section{INTRODUCTION}

Vitamin $\mathrm{D}_{3}$ (vitD; Figure 1) is well known for its importance in intestinal calcium absorption (Bouillon et al., 2003) and its modulation of the cell cycle (Pols et al., 1990). It also shows beneficial effects in multiple sclerosis (Rigby et al., 1987), diabetes (Mathieu and Badenhoop, 2005), cancer (Schwartz et al., 1997), and bacterial infections (White, 2008). Vitamin $\mathrm{D}_{3}$ deficiency is, however, a common problem. Sunlight is essential for biosynthesis of vitD, and low sun exposure at northern latitudes during the winter months leads to chronic population-wide deficiency. Because only a few foods contain vitD and often in small amounts, fortification of foods with vitD can potentially help overcome this problem. Vitamin $\mathrm{D}_{3}$ is a large and hydrophobic sterol molecule with poor water solubility that is easily degraded by light and oxygen, which makes fortification in clear drinks a difficult task. Techniques to stabilize and solubilize vitD with natural food components are therefore necessary. Several approaches have been investigated to solve this problem. Some of these exploit the ability of the milk proteins $\alpha$-LA (Delavari et al., 2015) and $\beta$-LG (Wang et al., 1997) to bind vitD. Other approaches include reassembly of casein micelles (Haham et al., 2012) to entrap vitD, protein complex formation via electrostatic interaction (Diarrassouba et al., 2015a), protein-polysaccharide nanoparticles (Lee and Hong, 2009), and a $\beta$-LG coagulum (Diarrassouba et al., 2015b). However, for many of the methods, it remains a challenge to obtain satisfactory vitD stability (Wang et al., 1997; Lee and Hong, 2009; Delavari et al., 2015), bioavailability (Wang et al., 1997; Delavari et al., 2015), pH stability (Haham et al., 2012; Diarrassouba et al., 2015a), and small enough particles to maintain a clear solution (Diarrassouba et al., 2015b).

$\alpha$-Lactalbumin has, for a long time, been known to form a complex with oleate (OA; Figure 1) known as HAMLET (human $\alpha$-LA made lethal to tumor cells; Håkansson et al., 1995). A broader class of protein- 

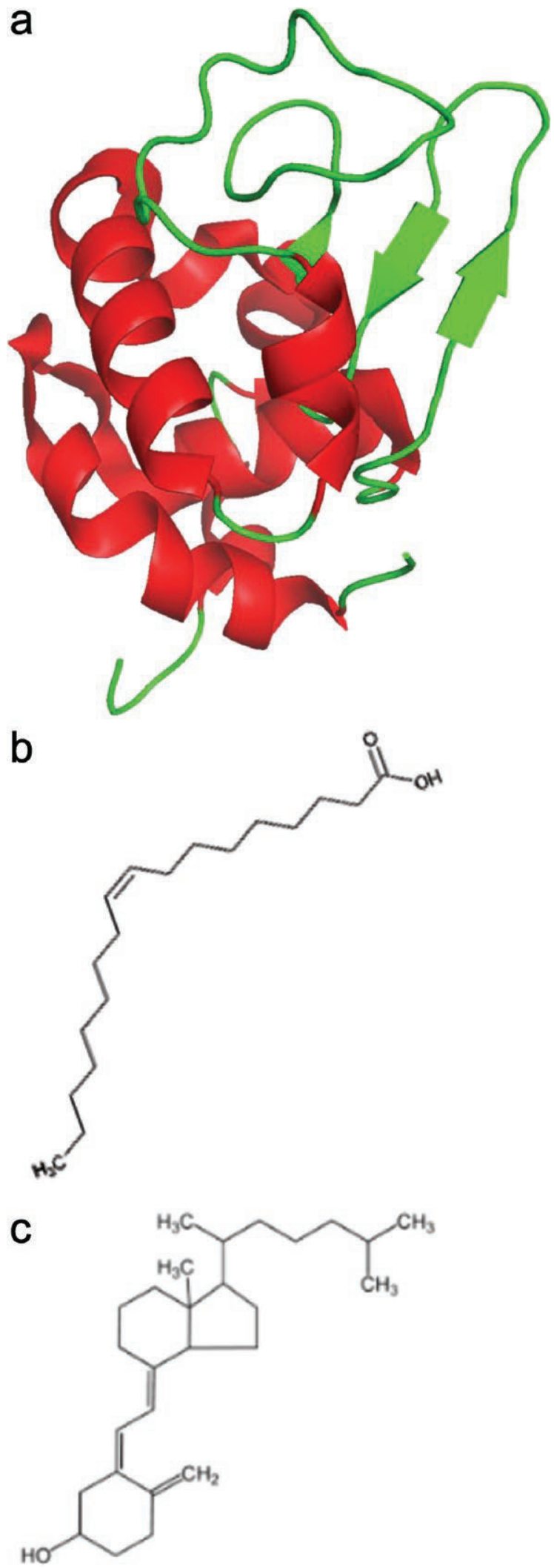

Figure 1. Structure of (a) apo- $\alpha-L A$ (PDB 1f6r) and stick representations of (b) oleic acid and (c) vitamin D. Color version available online. lipid complexes known as liprotides has recently been shown to be similar to HAMLET in terms of structure and cellular toxicity (Kaspersen et al., 2014). These liprotides can be formed by a range of proteins (Wilhelm et al., 2009; Permyakov et al., 2012; Kaspersen et al., 2014) and fatty acids (Svensson et al., 2003; Brinkmann et al., 2013; Frislev et al., 2016) and consist of a micelle core of fatty acid surrounded by partially denatured proteins (Kaspersen et al., 2014). Recently we have shown that liprotides consisting of $\alpha$-LA and OA can sequester and stabilize 2 hydrophobic vitamins, $\alpha$-tocopherol and retinaldehyde, and transfer them efficiently to phospholipid membranes (Pedersen et al., 2015). Oleate is an easily accessible fatty acid that can be extracted from several different sources such as olive oil (Beltran et al., 2004), and $\alpha$-LA is very abundant in whey (de Wit, 1998). Because liprotides can be formed from readily available food components, they may be good candidates for stabilization of vitD in clear beverages. Therefore, we hypothesize that liprotides will be able to significantly prolong the lifetime of vitD under otherwise detrimental conditions (prolonged storage, elevated temperature, and UV light).

Motivated by this hypothesis, the present study describes our attempts to stabilize vitD using liprotides consisting of different fatty acids and proteins. In addition to $\alpha-\mathrm{LA}$, we investigated liprotides containing the proteins BSA and $\beta-\mathrm{LG}$, which are easily accessible whey proteins. Five different cis fatty acids with variable chain length and saturation [OA (C18:1), linoleic acid (C18:2), cis-palmitoleic acid (cPA, C16:1), cisvaccenic acid (cVA, 18:1), eicosenoic acid (EI, C10:1)] were used to prepare the liprotides. We determined the solubility and stability of vitD in these different liprotides to find the most suitable liprotide composition. The most promising liprotide turned out to be that of $\alpha-\mathrm{LA}$ and OA. The structure and stoichiometry of this liprotide in complex with vitD was elucidated by chromatography and small-angle x-ray scattering (SAXS). We challenged the stability of vitD in this complex in different ways. These included exposure to $\mathrm{Ca}^{2+}$ (because native $\alpha$-LA has a $\mathrm{Ca}^{2+}$ binding site, unlike $\alpha$-LA in liprotides), BSA (which binds fatty acids), low $\mathrm{pH}$, and UHT.

\section{MATERIALS AND METHODS}

\section{Materials}

The $\mathrm{Ca}^{2+}$-depleted $\alpha$-LA from bovine milk $(\geq 85 \%$ pure), BSA ( $\geq 96 \%$ pure), essentially fatty acid free BSA ( $\geq 96 \%$ pure), $\beta$-LG ( $\geq 90 \%$ pure), IgG ( $\geq 95 \%$ pure), OA ( $\geq 95 \%$ pure), linoleic acid ( $\geq 99 \%$ pure), cis-palmitoleic acid (cPA, $\geq 98.5 \%$ pure), cVA ( $\geq 97 \%$ 
pure), EI ( $\geq 99 \%$ pure), and cholecalciferol vitD ( $\geq 98 \%$, C9756) were from Sigma-Aldrich (St. Louis, MO). 1,2-Dioleoylphosphatidylglycerol (DOPG, 840475P) and 1,2-dioleoylphosphatidylcholine (DOPC, 850757P) were from Avanti Polar Lipids (Alabaster, AL). All other reagents were of high purity or HPLC grade.

\section{Liprotide Preparation}

The OA $(38 \mathrm{mg} / \mathrm{mL})$ was dissolved in $20 \%$ ethanol. Linoleic acid $(71 \mathrm{mg} / \mathrm{mL}), \mathrm{cPA}(71 \mathrm{mg} / \mathrm{mL}), \mathrm{cVA}(71$ $\mathrm{mg} / \mathrm{mL})$, and EI $(71 \mathrm{mg} / \mathrm{mL})$ were dissolved in $96 \%$ ethanol. Then, $6 \mathrm{mg} / \mathrm{mL} \alpha$-LA or BSA was mixed with $1.5 \mathrm{mg} / \mathrm{mL}$ fatty acid in $50 \mathrm{mM} \mathrm{NaHPO}_{4}$, pH 7.4, 150 $\mathrm{m} M \mathrm{NaCl}$ (PBS), and incubated for $30 \mathrm{~min}$ at 80 and $90^{\circ} \mathrm{C}$, respectively. The $\alpha$-LA-OA mixtures were also prepared at room temperature. For $\beta-\mathrm{LG}, 6 \mathrm{mg} / \mathrm{mL}$ of protein was mixed with $1.5 \mathrm{mg} / \mathrm{mL}$ of $\mathrm{OA}$ in $10 \mathrm{mM}$ $\mathrm{KOH}(\mathrm{pH} 10.5)$ and incubated at $45^{\circ} \mathrm{C}$ for $30 \mathrm{~min}$. The $\beta$-LG sample was allowed to cool, after which $50 \mathrm{mM}$ $\mathrm{NaHPO}_{4}$ and $150 \mathrm{mM} \mathrm{NaCl}$ were added and $\mathrm{pH}$ was adjusted to 7.4 using $\mathrm{HCl}$. Samples for gel filtration were prepared using $2 \mathrm{mg} / \mathrm{mL}$ of $\alpha$-LA mixed with 1.7 $\mathrm{mg} / \mathrm{mL}$ of $\mathrm{OA}$ and incubated at $80^{\circ} \mathrm{C}$ for $1 \mathrm{~h}$.

\section{Turbidity Assay}

Vitamin $\mathrm{D}_{3}$ was dissolved in $96 \%$ ethanol to a concentration of $115 \mathrm{mM}$ and diluted further using MilliQ water. The formed liprotides with a final concentration of $4 \mathrm{mg} / \mathrm{mL}$ were mixed with different amounts of vitD in a 96-well clear-bottomed plate. To evaluate the turbidity of the samples, absorbance at $600 \mathrm{~nm}$ was measured at room temperature on a Varioskan Flash Multimode Reader (Thermo Scientific, Waltham, MA) over a period of $10 \mathrm{~h}$ with measurements every $10 \mathrm{~min}$. All experiments were carried out in triplicate and standard deviations are shown.

\section{Stability Assay}

Vitamin D $(280 \mu M)$ was mixed with $4 \mathrm{mg} / \mathrm{mL}$ of protein or liprotide. Vitamin D in PBS was used as a reference. Samples were left at room temperature $\left(20^{\circ} \mathrm{C}\right)$ or heated to the desired temperature and samples were collected at different time points. The amount of intact vitD was evaluated with HPLC. The experiments were carried out in triplicate and the time to reach half the initial vitD concentration (half-life, $\mathbf{t}_{1 / 2}$ ) was determined by fitting an exponential decay function (Amp $\times \exp ^{-\ln (2) \times t / t_{1 / 2}}$, where Amp is the amplitude) to the data. All samples were wrapped in foil to mini- mize exposure to light. All experiments were carried out in triplicate and standard deviations are shown.

\section{BSA and $\mathrm{Ca}^{2+}$ Stability Assay}

Vitamin D $(70 \mu M)$ was mixed with $1 \mathrm{mg} / \mathrm{mL}$ $\alpha$-LA-OA liprotide formed at either $20^{\circ} \mathrm{C}$ (lip20) or $80^{\circ} \mathrm{C}$ (lip80). Vitamin $\mathrm{D}_{3}$ in PBS buffer and $100 \mu M$ $\mathrm{CaCl}_{2}\left(\mathrm{Ca}^{2+}\right)$ was used as a reference. Samples were then mixed with either $4 \mathrm{mg} / \mathrm{mL}$ fatty acid-free BSA or $100 \mu M \mathrm{Ca}^{2+}$. Samples were stored wrapped in foil at room temperature and samples taken out over time and measured with HPLC to evaluate vitD content.

\section{UV Stability Assay}

Vitamin D $(280 \mu M)$ was mixed with $4 \mathrm{mg} / \mathrm{mL}$ protein or liprotide. Vitamin $\mathrm{D}_{3}$ in PBS was used as a reference. Samples were exposed to UV light (254 $\mathrm{nm})$ at $17 \mathrm{~W} / \mathrm{m}^{2}$. Samples were taken at different time points and the amount of intact vitD was evaluated with HPLC. All experiments were carried out in triplicate and standard deviations are shown.

\section{HPLC Analysis}

The OA, $\alpha-L A$, and vitD contents of samples were determined using an UltiMate 3000 HPLC (Dionex, Sunnyvale, CA) system with a Kinetex 2.6u C18 100 Å column, $75 \times 2.1 \mathrm{~mm}$ (Phenomenex, Torrance, CA). The mobile phase was a gradient of buffer A $(0.1 \%$ trifluoroacetic acid in Milli-Q) to buffer B (0.1\% trifluoroacetic acid in acetonitrile; $20-100 \%$ B over 3 min followed by $7 \mathrm{~min}$ at $100 \% \mathrm{~B}$ and an equilibration step at $20 \%$ for $5 \mathrm{~min}$ ). The flow rate was set to $0.3 \mathrm{~mL} /$ min and the injection volume to $20 \mu \mathrm{L}$. The calibration curves for $\alpha-\mathrm{LA}, \mathrm{OA}$, and vitD were linear, with $\mathrm{R}^{2}=$ 0.99 .

\section{Gel Filtration}

Prior to gel filtration, samples were centrifuged at $12,100 \times g$ for $8 \mathrm{~min}$ at room temperature. The samples were then injected onto a Superdex 200 column (GE Healthcare, Little Chalfont, UK) through a $250-\mu \mathrm{L}$ loop with a flow rate of $0.5 \mathrm{~mL} / \mathrm{min}$. The column was pre-equilibrated in PBS and protein elution was followed at $280 \mathrm{~nm}$. Fractions were collected and, when needed, concentrated using an Amicon ultra centrifugal filter (Merck Millipore, Cork, Ireland) with a 3-kDa cutoff. Protein concentrations were determined using both HPLC and the CB- $\mathrm{X}_{\mathrm{tm}}$ Protein Assay kit (G-Biosciences, St. Louis, MO). A concentration of 2 
$\mathrm{mg} / \mathrm{mL} \alpha-\mathrm{LA}$ with an $\alpha$-LA:OA:vitD molar ratio of 1:50:2 was used to compare liprotides with and without vitD and to determine the $\alpha$-LA:OA:vitD stoichiometry of the liprotides after formation. Samples for determining transfer of vitD to vesicles had a protein concentration of $0.4 \mathrm{mg} / \mathrm{mL}$, an $\alpha$-LA:OA:vitD molar ratio of 1:50:3, and a vesicle concentration of $2 \mathrm{mg} /$ $\mathrm{mL}$. Fractions were collected and evaluated for vitD and $\alpha$-LA content using HPLC. Six samples both with and without vitD were evaluated and standard deviations are shown.

\section{Small-Angle X-Ray Scattering}

Measurements were performed on a NanoSTAR SAXS from Bruker AXS with a liquid Ga jet source at a wavelength of $1.34 \AA$ (Schwamberger et al., 2015), installed at Aarhus University with home-built scatterless slits (Li et al., 2008). Liprotides were mixed at a 1:12:1 $\alpha$-LA:OA:vitD molar ratio at a protein concentration of $3 \mathrm{mg} / \mathrm{mL}$. For $\mathrm{Ca}^{2+}$ stability measurements, $\mathrm{CaCl}_{2}$ was added. For control spectra, calcium soap was prepared by mixing $0.2 \mathrm{mM} \mathrm{\textrm {Ca } ^ { 2 + }}$ with $0.4 \mathrm{mM} \mathrm{OA}$, and native $\alpha$-LA was prepared by mixing $3 \mathrm{mg} / \mathrm{mL} \alpha-\mathrm{LA}$ with 0.3 $\mathrm{m} M \mathrm{Ca}^{2+}$. For samples containing $\mathrm{Ca}^{2+}$, a $50 \mathrm{~m} M$ Tris, $\mathrm{pH} 7.4,150 \mathrm{~m} M \mathrm{NaCl}$ buffer was used to measure the incorporation of vitD. The acquisition time was 2 to 10 min at $20^{\circ} \mathrm{C}$. The buffer solution was measured over the same period and subtracted to provide the scattering of the particles. Conversion of scattering to absolute scale was done using water as a standard. The intensity is plotted as a function of the scattering vector $q$ that depends on the scattering angle $2 \theta: q=4 \pi \sin \theta / \lambda$. Model-independent information was obtained using the indirect Fourier transformation procedure that gives the pair distance distribution function $p(r)$ (Glatter, 1977), which is a histogram of distances between pair of points multiplied by the excess scattering length at the points. The function provides information about the shape and size of the particles.

The liprotides were modeled as core-shell particles (Kaspersen et al., 2014). The core consists of the hydrocarbon tail of $\mathrm{OA}$ and the large hydrophobic region of vitD, whereas the shell consists of partially denatured protein. This model was used for both liprotides with and without vitD. For samples where $\mathrm{Ca}^{2+}$ was added, the trend of the data suggested coexistence of 3 different species in the sample, namely intact liprotides, native $\alpha-\mathrm{LA}$, and calcium soap. Therefore, a linear combination of SAXS data for the 3 species was fitted to the SAXS data of the samples with increasing amounts of $\mathrm{Ca}^{2+}$, allowing a distribution of the different species to be determined.

\section{Tryptophan Fluorescence}

Tryptophan fluorescence was measured on Cary Eclipse fluorescence spectrometer (Agilent Technologies, Santa Clara, CA) with excitation at $280 \mathrm{~nm}$ and emission at 333 and $345 \mathrm{~nm}$. Spectra were recorded with slit widths of $2.5 \mathrm{~nm}$ (excitation) and $5 \mathrm{~nm}$ (emission) at $20^{\circ} \mathrm{C}$. Samples were first purified with gel filtration, and Trp fluorescence was then measured at a protein concentration of $0.5 \mathrm{mg} / \mathrm{mL}$. The $\mathrm{Ca}^{2+}$ at a molar ratio of $1: 1 \alpha-\mathrm{LA}: \mathrm{Ca}^{2+}$ was added at the indicated time point.

\section{pH Stability}

Liprotides were formed by mixing a molar ratio of 1:50 $\alpha$-LA:OA with a protein concentration of $2 \mathrm{mg} /$ $\mathrm{mL}$ in $10 \mathrm{mM} \mathrm{NaH} \mathrm{PO}_{4}, \mathrm{pH} 7.4,150 \mathrm{mM} \mathrm{NaCl}$ followed by incubation at $80^{\circ} \mathrm{C}$ for $1 \mathrm{~h}$. Subsequently, the $\mathrm{pH}$ was changed using either $50 \mathrm{~m} M \mathrm{NaH}_{2} \mathrm{PO}_{4}, \mathrm{pH} 7$, $50 \mathrm{~m} M 2$-( $N$-morpholino)ethanesulfonic acid, $\mathrm{pH} 6,50$ $\mathrm{m} M$ acetic acid, $\mathrm{pH} 5,50 \mathrm{~m} M$ acetic acid, $\mathrm{pH} 4$, or 50 $\mathrm{m} M$ glycine, $\mathrm{pH} 3$, and incubated $1 \mathrm{~h}$. Solutions were then loaded on a Superdex 200 column equilibrated in the same buffer as the sample or in $50 \mathrm{mM} \mathrm{NaH}{ }_{2} \mathrm{PO}$, $\mathrm{pH} 7.4,150 \mathrm{~m} M \mathrm{NaCl}$.

\section{Vesicle Preparation}

Two-hundred-nanometer large unilamellar vesicles (LUV) were prepared by first mixing $8 \mathrm{mg} / \mathrm{mL}$ of DOPC with $2 \mathrm{mg} / \mathrm{mL}$ of DOPG in chloroform. The chloroform was then evaporated and the phospholipid resuspended in PBS at $10 \mathrm{mg} / \mathrm{mL}$. The sample was vortexed and subject to 10 freeze-thaw cycles in liquid nitrogen and a water bath at $50^{\circ} \mathrm{C}$. Finally, the suspension was extruded 21 times through a 200-nm filter on an Avanti Mini-extruder (Avanti Polar Lipids, Alabaster, AL). Vesicles were stored at $4^{\circ} \mathrm{C}$ for up to 1 wk until use.

\section{Ultracentrifugation}

Ultracentrifugation was used to separate vesicles from liprotides (Pedersen et al., 2015). A $2 \mathrm{mg} / \mathrm{mL}$ solution of LUV was incubated with $0.05 \mathrm{mg} / \mathrm{mL}$ of gel filtration-purified $\alpha$-LA-OA liprotide containing 2.5 $\mu M$ vitD. As a control, LUV were incubated with vitD alone, vitD together with $\alpha$-LA, or vitD together with OA. The VitD without LUV was also included as a control. All samples were centrifuged at 306,000 $\times g$ for $1 \mathrm{~h}$ at $4^{\circ} \mathrm{C}$ in an Optima MAX-E preparative ultracentrifuge (Beckman Coulter, Indianapolis, IN). The 
A

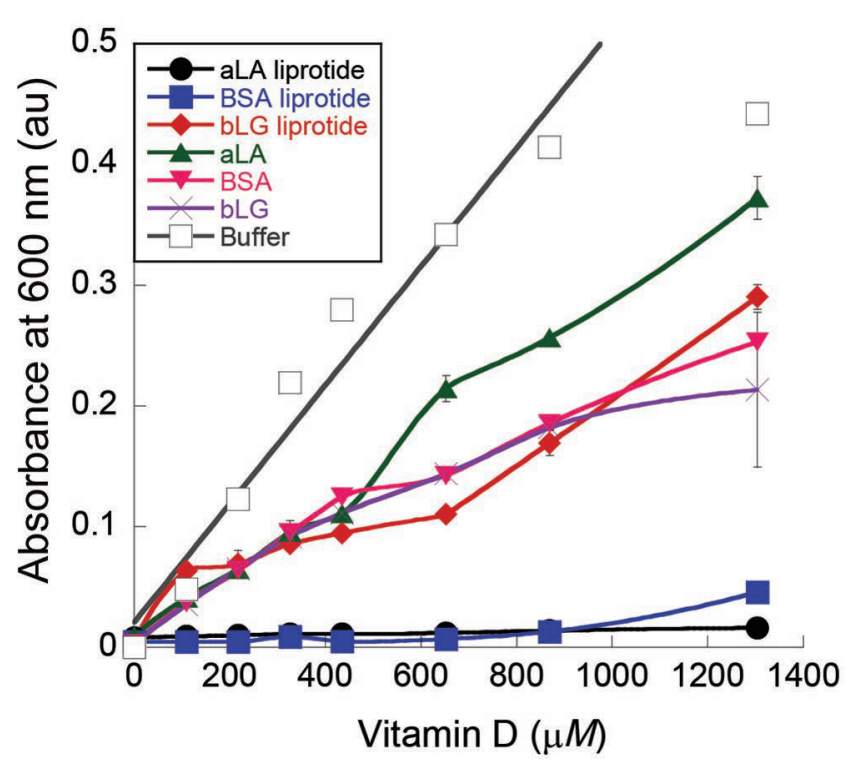

B

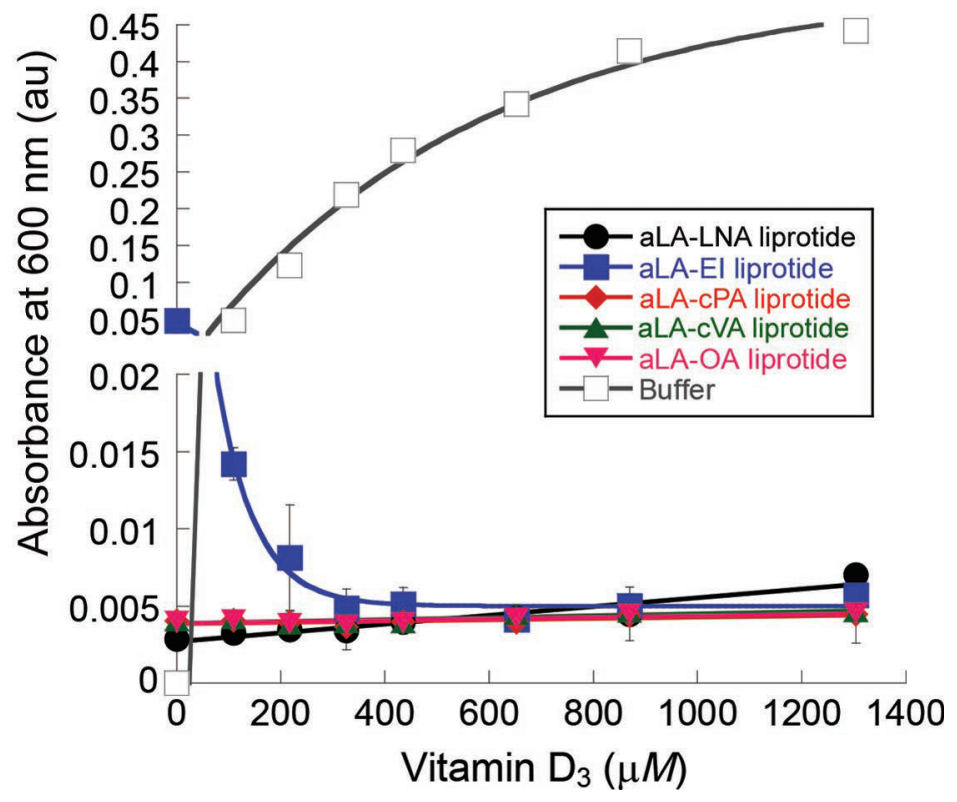

Figure 2. Turbidity of vitamin $\mathrm{D}_{3}$ (vitD) samples in the presence of different proteins and fatty acids measured by absorbance at $600 \mathrm{~nm}$. (A) Different proteins, either alone or as liprotides with oleate $(\mathrm{OA})$. (B) Liprotides formed by $\alpha$-LA (aLA) with different fatty acids. bLG $=$ $\beta$-LG; LNA = linoleic acid; $\mathrm{EI}=$ eicosenoic acid; $\mathrm{cPA}=$ cis-palmitoleic acid; cVA $=$ cis-vaccenic acid; au $=$ arbitrary units. Error bars indicate $\mathrm{SD}$ of triplicates. Color version available online.

supernatant was removed and the pellet resuspended in PBS. The vitD content in both supernatant and pellet was evaluated with HPLC of triplicate samples and the standard deviation is shown.

\section{RESULTS AND DISCUSSION}

\section{Liprotides Solubilize vitD}

When diluted in water, vitD aggregates and forms a turbid solution. In contrast, liprotides form a clear solution. We monitored absorbance at $600 \mathrm{~nm}$ as an indication of turbidity and used it to determine if vitD could be solubilized by liprotides and form a clear solution. In buffer alone, vitD showed an approximately linear increase $\left(\mathrm{R}^{2}=0.96\right)$ in turbidity with increasing vitD concentration up to $\sim 800 \mu M$ (Figure $2 \mathrm{~A}$ ). Incubation of vitD with proteins alone (without OA) reduced turbidity only slightly compared with free vitD. In contrast, $\alpha$-LA liprotides maintained low turbidity at all vitD concentrations used. The BSA liprotides also gave rise to low turbidity except for the highest amount of vitD used (1:21 BSA:vitD molar ratio), whereas the $\beta$-LG liprotides performed just as poorly as $\beta$-LG alone in terms of reducing vitD turbidity (Figure $2 \mathrm{~A}$ ). The solubilization of vitD when mixed with $\alpha$-LA liprotides occurred on the minute-hour scale: the absorbance decreased to zero with an apparent $t_{1 / 2}$ of 15 to 25 min for all vitD concentrations (Supplemental Figure S1; http://dx.doi.org/10.3168/jds.2016-11343). The $\beta$-LG liprotide was made at $\mathrm{pH} 10$ in contrast to the $\alpha-\mathrm{LA}$ and BSA liprotide that was formed at $\mathrm{pH}$ 7.4. Even though the overall structure of the liprotides is similar after different preparation methods (Kaspersen et al., 2014) and vitD is added at the same $\mathrm{pH}$ value, structural or chemical differences still might prevent vitD incorporation into liprotides previously formed at high $\mathrm{pH}$.

Next, we tested liprotides formed with different fatty acids for their ability to solubilize vitD. On the protein level, we confined ourselves to $\alpha$-LA, which had shown the greatest promise with OA (Figure 2A). We have recently shown that only unsaturated cis fatty acids form liprotides (Frislev et al., 2016). Consequently, we only formed liprotides with $\alpha$-LA using the cis-unsaturated fatty acids EI, linoleic acid, cPA, and cVA, and subsequently investigated the ability of these liprotides to solubilize vitD (Figure 2B). Liprotides with linoleic acid, cPA, or cVA all solubilized vitD equally well at the concentrations tested. The liprotides formed with EI showed a slightly higher level of turbidity, but this declined to the level of the other liprotides as vitD was added. Thus, all $\alpha$-LA-based liprotides and BSA-OA liprotides were able to solubilize vitD. 


\section{VitD Is Stabilized in the Liprotide Complex}

To follow up on these observations, we tested all liprotides except $\beta$-LG-OA for their ability to stabilize vitD against oxidative degradation during storage. We used an accelerated shelf-life test at $37^{\circ} \mathrm{C}$ with protection by native protein as control. In buffer, vitD was very unstable, leading to an apparent $t_{1 / 2}$ of only $\sim 0.75$ $\mathrm{h}$ (Figure 3A). Immunoglobulin G, used as a non-vitD binding control, only showed a small stabilizing effect with a $\mathrm{t}_{1 / 2}$ of $1.4 \mathrm{~h}$. The BSA, $\alpha-\mathrm{LA}$, and $\beta-\mathrm{LG}$ all bind vitD (Bikle et al., 1986; Wang et al., 1997; Delavari et al., 2015), and these 3 proteins by themselves led to an increase in vitD stability, increasing $t_{1 / 2}$ to $2.8,3.1$, and $3.6 \mathrm{~h}$, respectively. However, liprotides formed with BSA-OA and $\alpha-\mathrm{LA}-\mathrm{OA}$ increased stability to such a degree that only 69 and $73 \%$ was degraded, respectively, after a week. Changing the fatty acid in the $\alpha$-LA liprotide to linoleic acid, cVA, EI, or cVA did not markedly change the ability of liprotides to stabilize vitD (66, 90, 75, and 79\%, respectively, after 1 wk; Figure 3B), although linoleic acid performed slightly worse, and cVA slightly better, than the others. These experiments were carried out in the dark. In the absence of light, the main degradation mechanism can be ascribed to oxygen, free radical generation, and oxidation (Ron et al., 2010). The high stability of vitD in the absence of light might therefore be attributed to the entrapment of vitD, causing it to be shielded from the environment (Dalsgaard et al., 2011).

Ultraviolet light rapidly degrades vitD (Renken and Warthesen, 1993), and we therefore also evaluated the ability of liprotides to protect vitD from UV light.
Samples containing vitD were exposed to 254-nm UV light and the stability of vitD was monitored at regular intervals (Figure 3C). Light from the sun at $254 \mathrm{~nm}$ is largely absorbed by the atmosphere, and the dose given in the experiment is therefore very high compared with normal $254 \mathrm{~nm}$ exposure, making it an accelerated version of a conventional UV stability study (Semo et al., 2007; Diarrassouba et al., 2015a). Exponential decays were fitted to the data to obtain $\mathrm{t}_{1 / 2}$. In buffer, vitD was rapidly degraded $\left(\mathrm{t}_{1 / 2}=3.3 \pm 0.2 \mathrm{~min}\right)$, whereas it was reasonably stabilized by the proteins $\mathrm{BSA}\left(\mathrm{t}_{1 / 2}=5.1 \pm\right.$ $0.5 \mathrm{~min}), \alpha-\mathrm{LA}\left(\mathrm{t}_{1 / 2}=5.9 \pm 0.7 \mathrm{~min}\right)$, and $\beta-\mathrm{LG}\left(\mathrm{t}_{1 / 2}\right.$ $=6.3 \pm 0.5 \mathrm{~min})$. The liprotides with $\alpha-\mathrm{LA}\left(\mathrm{t}_{1 / 2}=13.1\right.$ $\pm 0.4 \mathrm{~min})$ and $\mathrm{BSA}\left(\mathrm{t}_{1 / 2}=9.9 \pm 1.6 \mathrm{~min}\right)$ were even better at stabilizing vitD, further emphasizing their potential in food fortification with vitD. Amino acids with aromatic side chains and double bonds might be able to absorb part of the UV light and the high density of protein around vitD in the liprotide might therefore limit the UV absorption of vitD (Webb et al., 1989; Luo et al., 2012). Nevertheless, the 3- to 4-fold stabilization by liprotides against UV light (judged by the $t_{1 / 2}$ values) was substantially less than the estimated 200- to 1,000-fold stabilization during incubation at $37^{\circ} \mathrm{C}$.

Foodstuffs such as egg and bread show a large stabilizing effect on vitD, and it is possible to boil, fry, and bake vitD-containing bread and egg without a great loss of vitD (Jakobsen and Knuthsen, 2014). Vitamin $\mathrm{D}$ degradation is mainly an issue in clear beverages [e.g., $\beta$-LG or $\alpha$-LA are used to stabilize vitD; Wang et al., 1997; Delavari et al., 2015). Stabilizing vitD in liprotides, on the other hand, provides good protection for vitD while maintaining a clear solution.
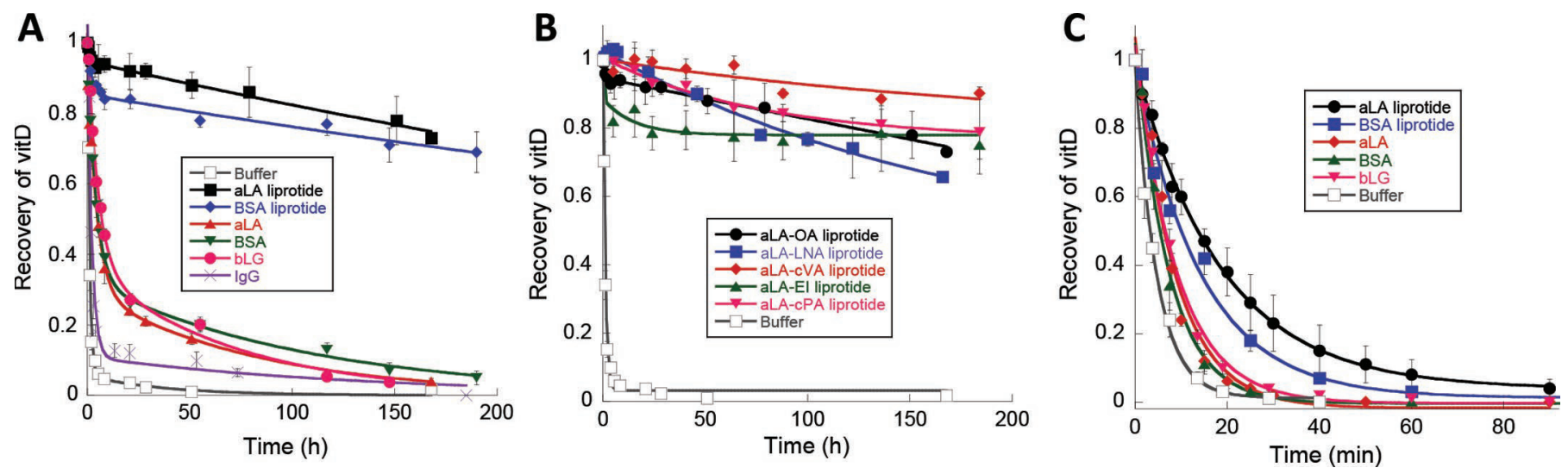

Figure 3. Change in the amount of intact vitamin $\mathrm{D}_{3}$ (vitD) over time in samples containing different proteins and fatty acids. (A,B) Samples incubated at $37^{\circ} \mathrm{C}$. (A) Different proteins, either alone or as liprotides with oleate (OA). (B) Liprotides formed by $\alpha$-LA with different fatty acids. (C) Samples exposed to 254-nm UV light. All data are normalized to the value at $0 \mathrm{~h}$. aLA $=\alpha$-LA; bLG $=\beta$-LG; LNA $=$ linoleic acid; $\mathrm{EI}=$ eicosenoic acid; $\mathrm{cPA}=$ cis-palmitoleic acid; $\mathrm{cVA}=$ cis-vaccenic acid; au = arbitrary units. Error bars indicate $\mathrm{SD}$ of triplicates. Color version available online. 


\section{VitD Does Not Alter Liprotide Structure}

Having established the functional advantage of incorporating vitD into liprotides, we investigated possible changes in liprotide structure and protein:fatty acid stoichiometry induced by incorporation of vitD. Earlier studies indicate that the $\alpha-\mathrm{LA}-\mathrm{OA}$ liprotide forms at least 2 species, depending on the mixing stoichiometry (Pedersen et al., 2015; Frislev et al., 2016). Of these, the smaller species corresponds to the "classical" liprotide core-shell structure, whereas the larger species is interpreted as a multi-layer liprotide (Frislev et al., 2016). These 2 species were also obvious from the gel-filtration chromatogram for the $\alpha$-LA-OA liprotide (Figure 4A). Addition of vitD led to only a slight peak shift, indicating slightly larger species, and an increase in the 280 $\mathrm{nm}$ signal that was most likely caused by vitD, which in ethanol has a molar extinction coefficient at $265 \mathrm{~nm}$ of $18,300 \mathrm{~mol}^{-1} \cdot \mathrm{L}^{-1}$. The content of the 2 peaks was evaluated using HPLC and showed that the smaller fraction contained $9.9 \pm 0.7 \mathrm{OA}$ per $\alpha$-LA and $0.6 \pm 0.2$ vitD per $\alpha$-LA; the corresponding numbers for the larger fraction were $20.7 \pm 2.1$ and $4.5 \pm 0.5$, respectively. These values are in excellent agreement with $\alpha$-LA-OA stoichiometries from our previous observations, where the large fraction contained $21 \pm 5$ OA per $\alpha$-LA and the smaller contained $9 \pm 1$ OA per $\alpha$-LA (Pedersen et al., 2015).

We used SAXS to determine whether vitD incorporation had an effect on the $\alpha$-LA-OA liprotide structure (Figure 4B,C). A molar ratio of 1:12 $\alpha$-LA:OA was used to prepare the core-shell liprotide. The liprotide without vitD gave rise to the characteristic core-shell liprotide signal (Figure 4B) characterized by a bump at $0.14 \AA^{-1}$, originating from the contrast sign difference of the alkyl core (a negative contrast due to lower electron density than water) and the protein shell (a positive contrast due to higher electron density than water). The liprotides with vitD also gave a characteristic core-shell liprotide signal, but had a slightly larger signal at high $q$-values than vitD-free liprotide. Vitamin $\mathrm{D}_{3}$ free in solution is mainly expected to affect the signal at high $q$-values (corresponding to smaller length scales than low $q$ signals) because of its much smaller size compared with the liprotide. To analyze whether the change in signal between liprotide with and without vitD was caused by free vitD in solution, we attempted to reconstruct the signal using a linear combination of signal from free vitD and liprotide without vitD. However, significant deviations were seen around 0.11 to $0.14 \AA^{-1}$ (Figure $4 \mathrm{~B}$ ), indicating that the liprotide and vitD are interacting to form a distinct new species as expected from the turbidity and recovery results. Nevertheless, the small changes in signal
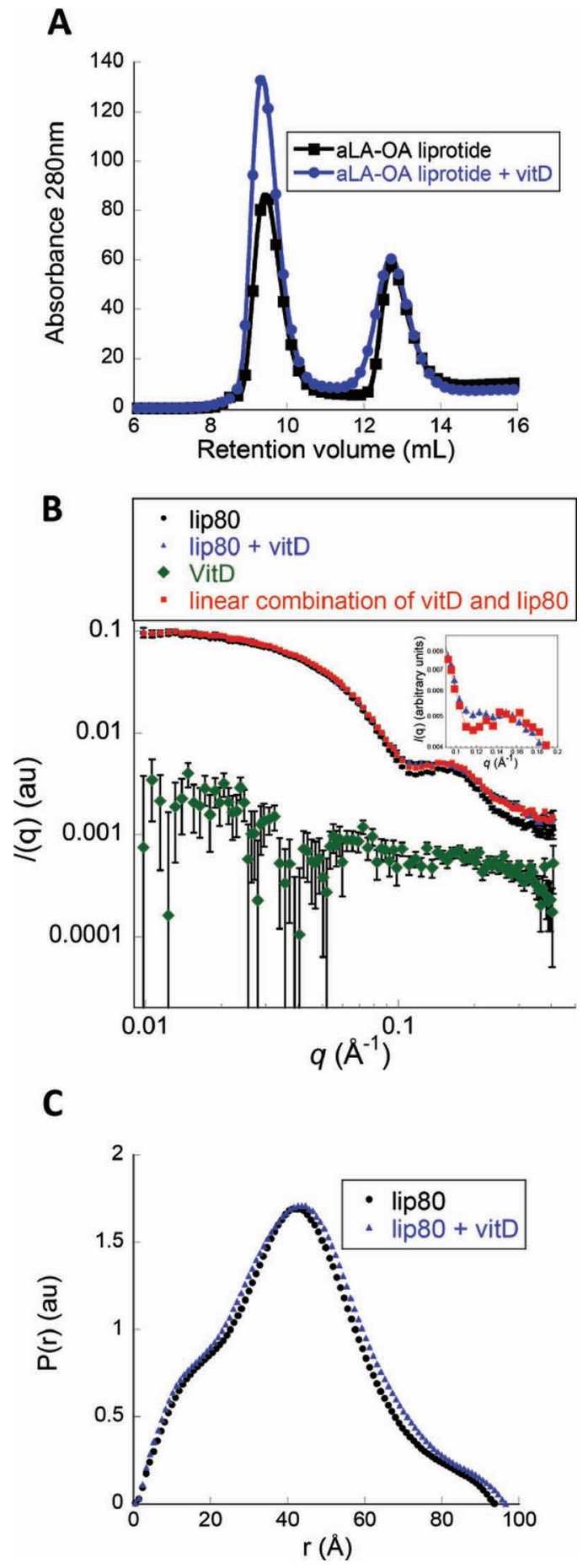

Figure 4. Liprotide structure. (A) Gel filtration chromatogram of the $\alpha$-LA-oleate (aLA-OA) liprotide incubated with and without vitamin $\mathrm{D}_{3}$ (vitD). The $\alpha$-LA monomer peak, which elutes around 17.5 $\mathrm{mL}$, is omitted for clarity. (B) Small-angle x-ray scattering (SAXS) analysis of liprotide with and without vitamin $\mathrm{D}$ and the linear combination of free vitamin D (contributing with 0.3) and liprotide (contributing with 1.0) giving best fit to the liprotide + vitamin D sample. (C) Pair distance distribution function $[\mathrm{p}(\mathrm{r})]$ of liprotide with and without vitamin D. $\operatorname{lip} 80=$ aLA-OA liprotide previously formed at $80^{\circ} \mathrm{C}$; au $=$ arbitrary units. Error bars indicate SD of triplicates. Color version available online. 
suggest that only minor structural changes take place in the liprotide when vitD interacts with the liprotide. This was further confirmed by the fact that the pair distance distribution functions $[\mathrm{p}(\mathrm{r})]$ of the liprotide with and without vitD were almost identical (Figure 4c). The liprotide-vitD complex was only very slightly larger $(85 \AA)$ than the normal liprotide $(83 \AA)$, which seems reasonable because the length of vitD is comparable to that of the alkyl chain of OA, which is much smaller than that of $\alpha$-LA (Figure 1). Earlier studies suggest that compounds that are incorporated into the liprotides need to have a high hydrophobicity as well as a uniform hydrophobic moiety (Pedersen et al., 2015). Vitamin $\mathrm{D}_{3}$ fulfills these requirements and most likely binds to the liprotides in the hydrophobic micellar core.

\section{Liprotides Are More Stable When Formed at $80^{\circ} \mathrm{C}$}

Many milk-based products are suitable for vitD fortification and it is therefore relevant to examine the effect of different milk constituents on liprotide and vitD stability. Milk contains a high amount of $\mathrm{Ca}^{2+}$, and because native $\alpha$-LA has a $\mathrm{Ca}^{2+}$ binding site that is absent in the unfolded state populated by $\alpha-\mathrm{LA}$ in liprotides, we decided to investigate the effect of $\mathrm{Ca}^{2+}$ on $\alpha$-LA-OA liprotide stability. Several different ways of forming the liprotides have been developed (Kaspersen et al., 2014), and we tested whether the strategy of formation had an influence on the ability of liprotides to withstand addition of $\mathrm{Ca}^{2+}$. We compared liprotides formed at 20 and $80^{\circ} \mathrm{C}$ and probed the tertiary structure using Trp fluorescence (Figure 5). In the liprotide structure, $\alpha$-LA has a Trp fluorescence peak maximum at around $345 \mathrm{~nm}$; the Trp peak of native $\alpha$-LA has a lower intensity and is shifted to around $333 \mathrm{~nm}$ (Kaspersen et al., 2014). Adding $\mathrm{Ca}^{2+}$ to the liprotide formed at $20^{\circ} \mathrm{C}$ lowered fluorescence intensity by $\sim 40 \%$ (Figure 5A) and shifted the peak maximum toward 333 $\mathrm{nm}$, indicating that the protein had transformed to a more native-like fold. Repeating this with liprotides formed at $80^{\circ} \mathrm{C}$, we only saw a $\sim 4.5 \%$ decrease in intensity (Figure 5B), which could be ascribed to the $4 \%$ dilution of the sample. This indicates that the partially unfolded state was unaffected by $\mathrm{Ca}^{2+}$. To confirm this, we investigated liprotide structure with SAXS before and after $\mathrm{Ca}^{2+}$ addition (Figure 5C,D). For the liprotide formed at $80^{\circ} \mathrm{C}$, we observed only a small difference before and after $\mathrm{Ca}^{2+}$ addition, indicating only small rearrangements in the structure. In contrast, addition of $\mathrm{Ca}^{2+}$ to the liprotide formed at $20^{\circ} \mathrm{C}$ caused larger changes with a lower intensity at low $q$-values, indicating formation of smaller structures, and also a sharp diffraction signal at $0.13 \AA^{-1}$, indicating formation of structures with a regular $48 \AA$ spacing $(\mathrm{d}=2 \pi / \mathrm{q})$. It is well known that calcium soap can be formed when $\mathrm{Ca}^{2+}$ and OA interact to form repeated structures of OA-Ca ${ }^{2+}$ bilayers. The SAXS measurements on pure OA-Ca ${ }^{2+}$ samples also showed the characteristic 0.13 $\AA^{-1}$ peak (Supplemental Figure S2; http://dx.doi. org/10.3168/jds.2016-11343). In fact, a linear combination of the SAXS spectra of native $\alpha$-LA, liprotide, and $\mathrm{OA}-\mathrm{Ca}^{2+}$, together with a constant background, were sufficient to reproduce the SAXS spectra recorded after mixing lip20 with $\mathrm{Ca}^{2+}$ (Figure 5E). This indicates that addition of $\mathrm{Ca}^{2+}$ to the lip20 sample causes release of $\alpha-\mathrm{LA}$ and formation of $\mathrm{OA}-\mathrm{Ca}^{2+}$ complexes. At high $\mathrm{Ca}^{2+}$ concentrations, the low $q$ region is fitted more poorly. The native $\alpha$-LA SAXS data has a slope at low $q$-values indicating dimerization or aggregation in the sample, which might explain why the linear combination fits more poorly at low $q$-values. Results from the linear fitting combinations provided estimates of the composition at different $\mathrm{Ca}^{2+}$ concentrations (Figure $5 \mathrm{~F}$ ), showing that the liprotide slowly changes to a monomer-like structure and that the OA interacts with $\mathrm{Ca}^{2+}$ to form calcium soap. The $\mathrm{Ca}^{2+}$ in the bilayer structure can bind $2 \mathrm{OA}$ and there are $10 \mathrm{OA}$ per $\alpha$-LA in each liprotide, whereas $\alpha$-LA has $2 \mathrm{Ca}^{2+}$ binding sites. Based on these numbers, a 1:7 $\alpha-\mathrm{LA}: \mathrm{Ca}^{2+}$ molar ratio should be enough to disrupt all liprotides in the solution. This fits well with a total disruption of the structure somewhere between a 1:4 and 1:10 $\alpha-\mathrm{LA}: \mathrm{Ca}^{2+}$ molar ratio.

The $\alpha$-LA in the liprotide formed at $20^{\circ} \mathrm{C}$ therefore seems to change back to its native conformation when $\mathrm{Ca}^{2+}$ is added, whereas the liprotides formed at $80^{\circ} \mathrm{C}$ do not markedly interact with $\mathrm{Ca}^{2+}$ at these molar ratios and retain their liprotide structure. Formation of liprotides at $80^{\circ} \mathrm{C}$ leads to a significant shuffling of the disulfide bonds, generating higher-order structures (Frislev et al., 2016). This may also prevent the conformational changes required to refold $\alpha-\mathrm{LA}$ and bind $\mathrm{Ca}^{2+}$, in contrast to the milder treatment at $20^{\circ} \mathrm{C}$, which leaves the covalent structure of $\alpha$-LA essentially unaltered.

Another component of milk is BSA (de Wit, 1998); BSA binds fatty acids and could disrupt liprotide structure by binding the fatty acid of the liprotide, leading to a breakdown of liprotide structure. To test this and to determine what effect $\mathrm{Ca}^{2+}$ would have on vitD stability, we formed liprotides at both 20 and $80^{\circ} \mathrm{C}$ and incubated them with vitD and either $\mathrm{Ca}^{2+}$ or fatty acid-depleted BSA (Figure 5G). Liprotides formed at 20 and $80^{\circ} \mathrm{C}$ stabilized vitD equally well and, after 20 d, $83 \pm 2 \%$ and $79 \pm 3 \%$ vitD remained, respectively. Addition of $\mathrm{Ca}^{2+}$ at a $\sim 1.4 \mathrm{Ca}^{2+}: \alpha-\mathrm{LA}$ ratio to the $80^{\circ} \mathrm{C}$ liprotides did not markedly alter the vitD stability $(75$ $\pm 4 \%$ left), whereas it significantly decreased the stabilizing effect of liprotides formed at $20^{\circ} \mathrm{C}(49 \pm 4 \%$ left $)$. 
According to the SAXS experiments, approximately 7 times more $\mathrm{Ca}^{2+}$ than used here would be needed to disrupt all the liprotides formed at $20^{\circ} \mathrm{C}$, explaining why the lip20 liprotide still gave some protection. Ad- dition of $4 \mathrm{mg} / \mathrm{mL}$ BSA $(\sim 1: 1$ molar ratio with $\alpha-\mathrm{LA})$ reduces vitD stability with $\operatorname{lip} 80(42 \pm 3 \%$ remaining $)$ and even more with lip20 ( $23 \pm 3 \%$ remaining). Nevertheless, in all cases, the liprotides provided significant
A

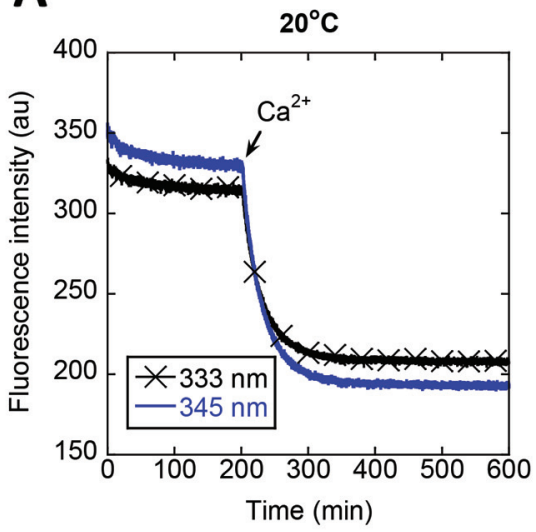

D

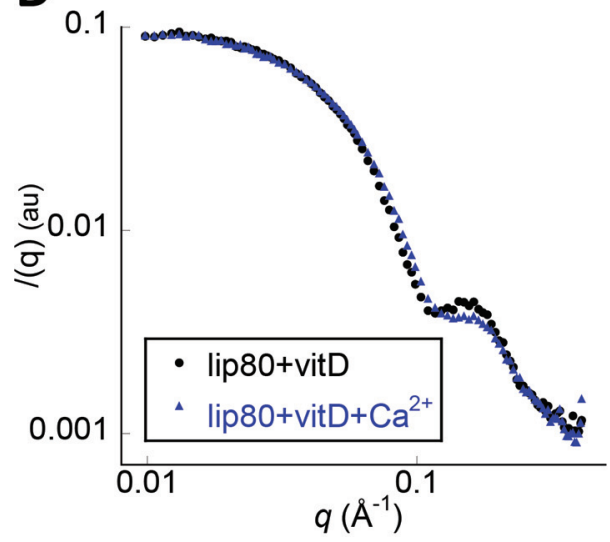

B

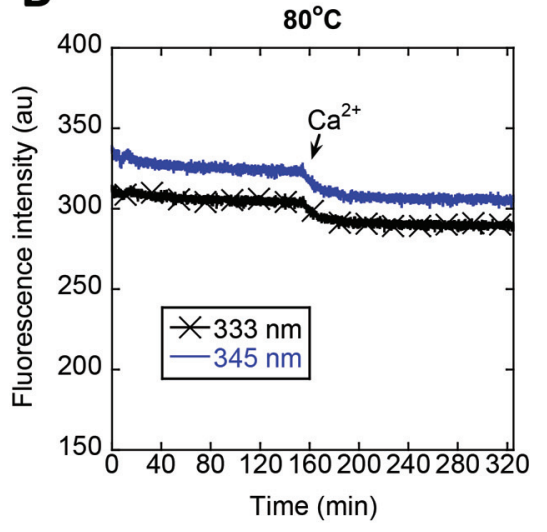

E

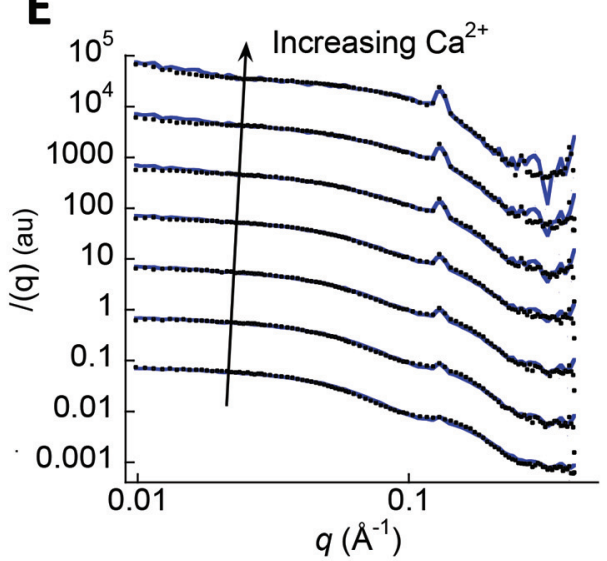

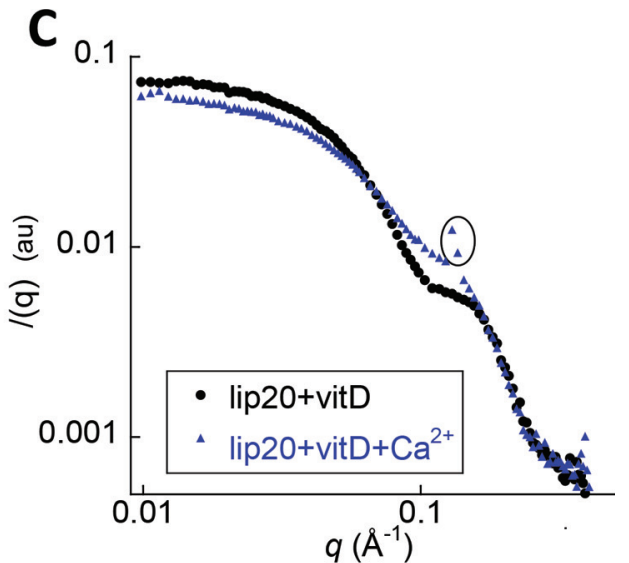

$\mathbf{F}$

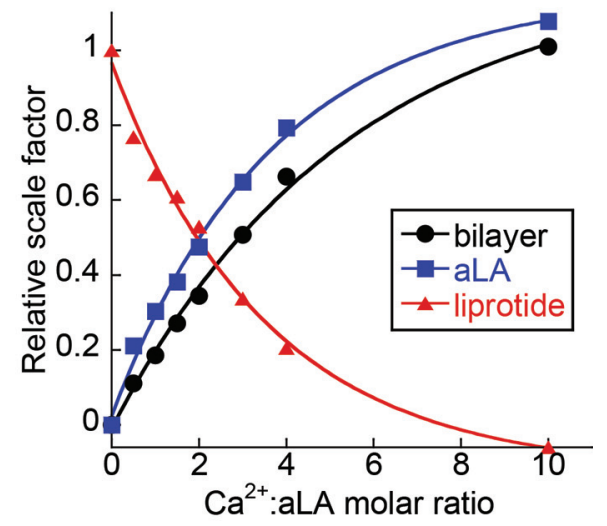

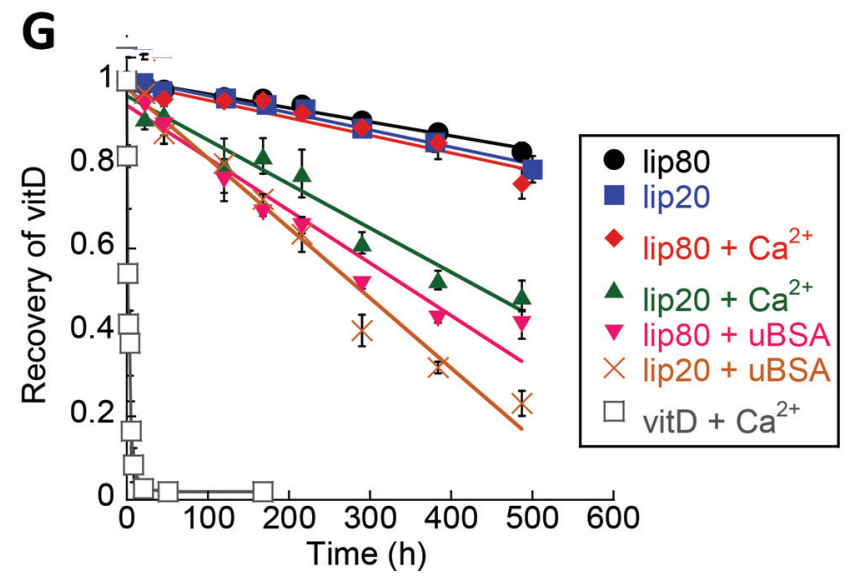

Figure 5. Stability of $\mathrm{Ca}^{2+}$ and BSA. (A,B) Tryptophan fluorescence intensity of $\alpha$-LA-oleate liprotides previously formed at $20^{\circ} \mathrm{C}($ lip20) and $80^{\circ} \mathrm{C}$ (lip80) upon addition of $\mathrm{Ca}^{2+}$ to a molar ratio of $1: 1 \alpha-\mathrm{LA}: \mathrm{Ca}^{2+}\left(\mathrm{Ca}^{2+}\right.$ addition indicated by arrow); au $=$ arbitrary units. (C,D) Small-angle x-ray scattering (SAXS) analysis of lip20 and lip80 with and without $\mathrm{Ca}^{2+}$. Proposed $\mathrm{Ca}^{2+}$ soap diffraction signal is circled. VitD $=$ vitamin $\mathrm{D}_{3}$. (E) Raw data (black) of lip20 incubated with different amounts of $\mathrm{Ca}^{2+}$ with best fit of linear combination of liprotide, native $\alpha$-LA, and oleic acid-Ca ${ }^{2+}$ (blue). (F) The contribution of liprotide, $\alpha$-LA (aLA), and oleic acid-Ca ${ }^{2+}$ to fitted spectra from panel E, based on linear combinations. (G) Change in the amount of vitD in $\alpha$-LA-oleate liprotides formed at either 20 or $80^{\circ} \mathrm{C}$ and incubated at $20^{\circ} \mathrm{C}$ with either $\mathrm{BSA}$ or $\mathrm{Ca}^{2+} ; \mathrm{au}=$ arbitrary units. Error bars indicate SD of triplicates. Color version available online. 
protection for vitD, and the liprotides still provided some stability for vitD at high BSA concentrations (4 $\mathrm{mg} / \mathrm{mL}$ ). Aside from using liprotides as hydrophobic transporters, liprotides have been explored for their toxicity toward cancer cells (Hakansson et al., 1995) and their antimicrobial properties (Marks et al., 2012) and have shown promise in vivo against bladder cancer (Mossberg et al., 2010). Using more stable liprotides formed at higher temperatures might improve these treatment methods, as liprotides used in vivo must be stable under various conditions that would otherwise disrupt the liprotides.

\section{Liprotides Protect vitD Against Heating}

Clear drinks such as juice and milk-based products often have a low $\mathrm{pH}$. We therefore decided to test the $\mathrm{pH}$ stability of the liprotide structure under acidic conditions. We formed liprotides at $\mathrm{pH} 7.4$ at $80^{\circ} \mathrm{C}$, then lowered the $\mathrm{pH}$ to between 3 and 7 and analyzed the size composition of the solutions by gel filtration (Figure 6A). At pH 7, the liprotide was still stable. However, at $\mathrm{pH} 6$, a broad smearing was seen, indicating the presence of many different species of different sizes. At lower $\mathrm{pH}$, only monomer $\alpha-\mathrm{LA}$ was seen, and at $\mathrm{pH} 3$ in particular (and to a lesser degree at $\mathrm{pH}$ 4), the peaks were shifted to higher retention volumes, suggesting interactions of $\alpha-\mathrm{LA}$ with the column. At $\mathrm{pH}<6$ a large amount of precipitation was seen. The carboxylic group of monomeric OA has an acid dissociation constant $\left(\mathrm{p} K_{\mathrm{a}}\right)$ of around 5 that shifts to 8.5 in free micelles (Fontana et al., 2013). In liprotides OA is deprotonated at $\mathrm{pH} 7.4$ (Ho et al., 2013), and this form is most likely required to form the micelle core of the liprotide structure, indicating that the micellar $\mathrm{p} K_{\mathrm{a}}$ is shifted to below 7.4 in liprotides. Because the liprotide structure is disrupted at a $\mathrm{pH}$ of 6 and lower, we concluded that the $\mathrm{p} K_{\mathrm{a}}$ of $\mathrm{OA}$ in the liprotide is close to 6 and the disruption of the complex happens because of protonation of OA. To check for reversibility, the liprotides were incubated at $\mathrm{pH} 3$ to 6 for 1 $\mathrm{h}$ before raising the $\mathrm{pH}$ to 7.4 (but without increasing the temperature to $80^{\circ} \mathrm{C}$ as was done to make the liprotides originally). Remarkably, the gel-filtration profiles revealed a recovery of liprotide size distribution at $\mathrm{pH} 7.4$ independent of their previous $\mathrm{pH}$ (Figure $6 \mathrm{~B})$, indicating that no irreversible structural changes happened at low $\mathrm{pH}$ and only reversible precipitation of OA occurred. Given that $\alpha-\mathrm{LA}$ is also able to take up $\mathrm{OA}$ to form liprotides at $20^{\circ} \mathrm{C}$, it is possible that a simple liprotide-based emulsification of $\mathrm{OA}$ and vitD has occurred upon restoration of neutral $\mathrm{pH}$.

The low $\mathrm{pH}$ found in many beverages reduces microbial growth and extends shelf life. A different way to ex-
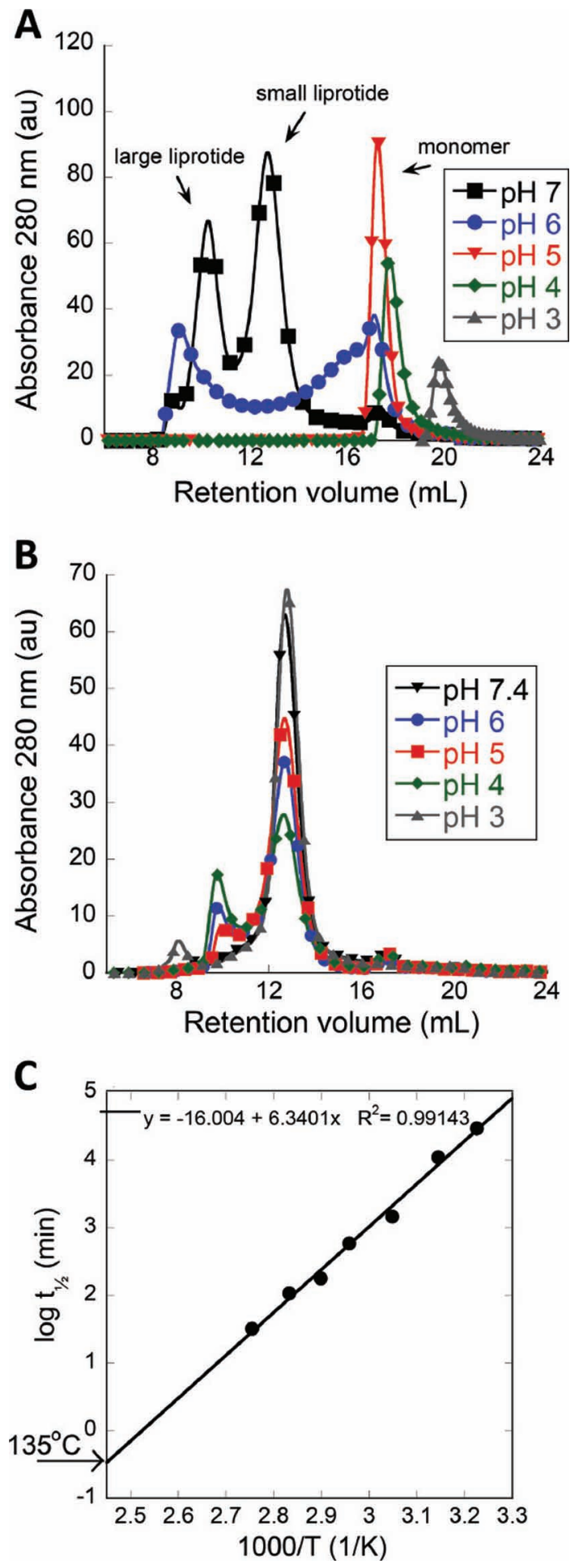

Figure 6. pH stability of liprotides. (A) Gel filtration chromatogram of liprotide formed at $80^{\circ} \mathrm{C}$ (lip80) at $\mathrm{pH} 7.4$ and subsequently incubated and run in $\mathrm{pH}$ buffers ranging from $\mathrm{pH} 3$ to 7. (B) Gel filtration chromatogram of lip80 incubated in $\mathrm{pH}$ buffers ranging from $\mathrm{pH} 3$ to 7 followed by incubation at $\mathrm{pH} 7.4$ and run on a column at $\mathrm{pH}$ 7.4. (C) Eyring plot of the temperature-dependence of $t_{1 / 2}$ for degradation of vitamin D in lip80; au = arbitrary units. $\mathrm{t}_{1 / 2}$ values obtained from plots in Supplemental Figure S2 (http://dx.doi.org/10.3168/jds.201611343). Color version available online. 
tend the shelf life of beverages is to use UHT processing where the products are heated to temperatures around $135^{\circ} \mathrm{C}$ for a few seconds. To estimate vitD stability in liprotides at $135^{\circ} \mathrm{C}$, we measured the stability of vitD over a temperature range of 37 to $90^{\circ} \mathrm{C}$ (Supplemental Figure S3; http://dx.doi.org/10.3168/jds.2016-11343) and determined $t_{1 / 2}$ at each temperature $(T)$. Good correlation was seen between the logarithm of $t_{1 / 2}$ and $1 / \mathrm{T}$ (Figure $6 \mathrm{C}$ ). Extrapolating this to $135^{\circ} \mathrm{C}$ predicts $\mathrm{t}_{1 / 2}{ }^{135 \mathrm{C}}=21 \pm \mathrm{s}$. This predicts that around 6 to $7 \%$ of vitD is degraded after UHT treatment for $2 \mathrm{~s}$ at this temperature. The liprotides therefore seem to be good candidates for long-time storage of vitD in products at neutral $\mathrm{pH}$.

\section{VitD Is Transferred to Phospholipid Membranes}

A general problem with vitD today is, however, its low bioavailability. We reasoned that complexation in liprotides might be able to improve this due to known interactions of liprotides with membranes (Nielsen et al., 2010; Pedersen et al., 2015). To evaluate if the vitD content of liprotides could be transferred to membranes, we investigated what happens when phospholipid membranes are incubated with the liprotides. To distinguish vesicle-bound material from free liprotides, we either separated the vesicle using gel filtration or ultracentrifugation (Figure 7). On a gel filtration column, the vesicles eluted in the void volume and were clearly separated from liprotide and monomer protein (Figure 7A). However, incubation of liprotide and vesicle to- gether resulted in a large decrease of the liprotide peaks together with an increase in the monomer peak, indicating that the liprotide structure had been disrupted. Fractions were collected and analyzed by HPLC. The small and large liprotide alone contained a molar ratio $\alpha$-LA:vitD of 1:0.8 and 1:4.7, respectively. When incubated with vesicles, the monomer peak contained no detectable vitD, whereas the vesicle peak contained a molar ratio $\alpha$-LA:vitD of $1: 7.5$, showing that all vitD had been transferred to the vesicle while releasing most of the protein. To confirm this, we used ultracentrifugation to pellet vesicles without pelleting liprotides and analyzed the supernatant and pellet fractions with HPLC (Figure 7B and Supplemental Figure S4; http:// dx.doi.org/10.3168/jds.2016-11343). When vitD was ultracentrifuged alone or in the presence of vesicle, hardly any vitD was recovered either in the supernatant or in the pellet (Supplemental Figure S4; http://dx.doi. org/10.3168/jds.2016-11343), indicating that vitD had been degraded and not transferred to the vesicle fraction. After incubation of liprotide and vesicle, it was found that $99 \pm 11 \%$ of $\alpha$-LA was found in the supernatant whereas only $1 \pm 1 \%$ was found associated with the vesicle; $89 \pm 4 \%$ of $\mathrm{OA}$ and $84 \pm 3 \%$ of vitD was found associated with the vesicle, whereas only 11 $\pm 3 \% \mathrm{OA}$ and $16 \pm 3 \%$ remained in the supernatant. Clearly, the vast majority of the hydrophobic liprotide components (OA and vitD) had been transferred to the vesicles, leaving all protein in solution.

Several studies have investigated the bioavailability of vitD in different foods and vehicles. An increase in
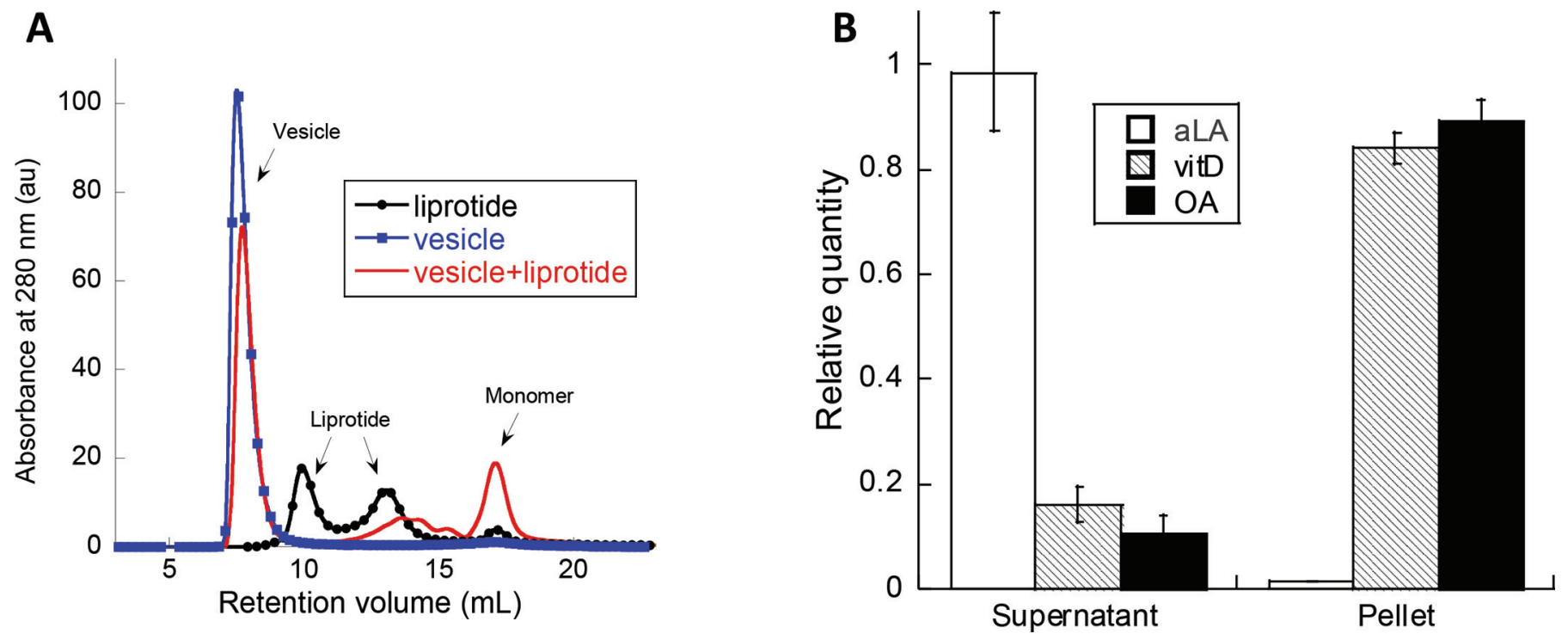

Figure 7. Transfer of content from liprotide to vesicle. (A) Gel filtration chromatogram of liprotide incubated with vesicles. (B) Amount of $\alpha$-LA (aLA), oleate (OA), and vitamin $\mathrm{D}_{3}$ (vitD) found in supernatant and pellet after ultracentrifugation of vesicles incubated with liprotide; $\mathrm{au}=$ arbitrary units. Error bars indicate SD of triplicates. Color version available online. 
bioavailability is often seen when vitD is packed in a hydrophobic environment such as a casein micelle (Haham et al., 2012) or a $\beta$-LG coagulum (Diarrassouba et al., 2015b). Vitamin $\mathrm{D}_{3}$ fortified in skim milk, orange juice, and corn oil all had levels of bioavailability, suggesting that fat is not an absolute prerequisite for good bioavailability (Tangpricha et al., 2003; Biancuzzo et al., 2010). In these systems, the greatest obstacle therefore seems to be the stability of vitD. However, liprotides containing vitD combine acceptable bioavailability with significant stabilization, making this formulation of vitD a good candidate for vitD fortification.

\section{CONCLUSIONS}

We have shown that vitD can be incorporated successfully into liprotides formed of $\alpha$-LA or BSA with different cis UFA. The liprotides are water soluble and transparent and protect vitD against elevated temperatures and UV light. No large difference was found in the degradation of vitD when liprotides were formed with different fatty acids, indicating that they provide the same protective hydrophobic environment overall. The liprotides are not stable at $\mathrm{pH} 6$ and lower, but should instead be used to stabilize vitD in solutions close to neutral $\mathrm{pH}$. The high stability of vitD in the liprotides suggests that UHT treatment is possible with only a small loss of vitD in the process, making products with long shelf life possible. Vitamin D most likely binds in the hydrophobic interior of the liprotide, shielding it from the surrounding medium and thus causing less oxidative degradation. Investigations into the structure and binding/sequestering environment of vitD in liprotides are currently underway to understand how the molecule is protected and to get a better understanding of what molecules might be incorporated in the structure in the future. Our results indicate that vitD may be encapsulated and stabilized for enrichment of clear beverages at neutral $\mathrm{pH}$ to improve the intake and bioavailability of vitD. This could be in a nutritional water drink where little fat is present, or as a high-concentration vitD liquid as an alternative to vitD tablets to improve uptake of vitD.

\section{ACKNOWLEDGMENTS}

This work was supported by the Danish Innovation Foundation (4105-00008B-DFORT; to J. N. Pedersen), the Danish Research Council | Technology and Production (DFF-4005-00479), and the Aarhus University Research Foundation (to D. E. Otzen).

\section{REFERENCES}

Beltran, G., C. Del Rio, S. Sanchez, and L. Martinez. 2004. Influence of harvest date and crop yield on the fatty acid composition of virgin olive oils from cv. Picual. J. Agric. Food Chem. 52:3434-3440.

Biancuzzo, R. M., A. Young, D. Bibuld, M. H. Cai, M. R. Winter, E. K. Klein, A. Ameri, R. Reitz, W. Salameh, T. C. Chen, and M. F. Holick. 2010. Fortification of orange juice with vitamin D-2 or vitamin D-3 is as effective as an oral supplement in maintaining vitamin D status in adults. Am. J. Clin. Nutr. 91:1621-1626.

Bikle, D. D., E. Gee, B. Halloran, M. A. Kowalski, E. Ryzen, and J. G. Haddad. 1986. Assessment of the free fraction of 25-hydroxyvitamin D in serum and its regulation by albumin and the vitamin D-binding protein. J. Clin. Endocrinol. Metab. 63:954-959.

Bouillon, R., S. Van Cromphaut, and G. Carmeliet. 2003. Intestinal calcium absorption: Molecular vitamin D mediated mechanisms. J. Cell. Biochem. 88:332-339.

Brinkmann, C. R., A. Brodkorb, S. Thiel, and J. J. Kehoe. 2013. The cytotoxicity of fatty acid/ $\alpha$-lactalbumin complexes depends on the amount and type of fatty acid. Eur. J. Lipid Sci. Technol. 115:591-600.

Dalsgaard, T. K., J. Sorensen, M. Bakman, C. Nebel, R. Albrechtsen, L. Vognsen, and J. H. Nielsen. 2011. Light-induced protein and lipid oxidation in low-fat cheeses: Whey proteins as antioxidants. Dairy Sci. Technol. 91:171-183.

de Wit, J. N. 1998. Marschall Rhone-Poulenc Award Lecture. Nutritional and functional characteristics of whey proteins in food products. J. Dairy Sci. 81:597-608.

Delavari, B., A. A. Saboury, M. S. Atri, A. Ghasemi, B. Bigdeli, A Khammari, P. Maghami, A. A. Moosavi-Movahedi, T. Haertle, and B. Goliaei. 2015. Alpha-lactalbumin: A new carrier for vitamin D3 food enrichment. Food Hydrocoll. 45:124-131.

Diarrassouba, F., G. Garrait, G. Remondetto, P. Alvarez, E. Beyssac, and M. Subirade. 2015a. Food protein-based microspheres for increased uptake of vitamin D3. Food Chem. 173:1066-1072.

Diarrassouba, F., G. Garrait, G. Remondetto, P. Alvarez, E. Beyssac, and M. Subirade. 2015b. Improved bioavailability of vitamin D3 using a beta-lactoglobulin-based coagulum. Food Chem. 172:361367.

Fontana, A., B. Spolaore, and P. Polverino de Laureto. 2013. The biological activities of protein/oleic acid complexes reside in the fatty acid. Biochim. Biophys. Acta 1834:1125-1143.

Frislev, H. S., C. M. Jessen, C. L. P. Oliveira, J. S. Pedersen, and D. E. Otzen. 2016. Liprotides made of alpha-lactalbumin and cis fatty acids form core-shell and multi-layer structures with a common membrane-targeting mechanism. Bba-Proteins Proteom. 1864:847-859.

Glatter, O. 1977. A new method for the evaluation of small-angle scattering data. J. Appl. Cryst. 10:415-421.

Haham, M., S. Ish-Shalom, M. Nodelman, I. Duek, E. Segal, M. Kustanovich, and Y. D. Livney. 2012. Stability and bioavailability of vitamin D nanoencapsulated in casein micelles. Food Funct. 3:737-744

Håkansson, A., B. Zhivotovsky, S. Orrenius, H. Sabharwal, and C. Svanborg. 1995. Apoptosis induced by a human milk protein. Proc. Natl. Acad. Sci. USA 92:8064-8068.

Ho, J. C., P. Storm, A. Rydstrom, B. Bowen, F. Alsin, L. Sullivan, I. Ambite, K. H. Mok, T. Northen, and C. Svanborg. 2013. Lipids as tumoricidal components of human alpha-lactalbumin made lethal to tumor cells (HAMLET): Unique and shared effects on signaling and death. J. Biol. Chem. 288:17460-17471.

Jakobsen, J., and P. Knuthsen. 2014. Stability of vitamin D in foodstuffs during cooking. Food Chem. 148:170-175.

Kaspersen, J. D., J. N. Pedersen, J. G. Hansted, S. B. Nielsen, S. Sakthivel, K. Wilhelm, E. L. Nemashkalova, S. E. Permyakov, E. A. Permyakov, C. L. Pinto Oliveira, L. A. Morozova-Roche, D. E. Otzen, and J. S. Pedersen. 2014. Generic structures of cytotoxic liprotides: Nano-sized complexes with oleic acid cores and shells of disordered proteins. ChemBioChem 15:2693-2702. 
Lee, A., and Y. Hong. 2009. Coacervate formation of $\alpha$-lactalbuminchitosan and $\beta$-lactoglobulin-chitosan complexes. Food Research International 42:733-738.

Li, Y. L., R. Beck, T. Huang, M. C. Choi, and M. Divinagracia. 2008. Scatterless hybrid metal-single-crystal slit for small-angle X-ray scattering and high-resolution X-ray diffraction. J. Appl. Cryst. 41:1134-1139.

Luo, Y., Z. Teng, and Q. Wang. 2012. Development of zein nanoparticles coated with carboxymethyl chitosan for encapsulation and controlled release of vitamin $\mathrm{D}_{3}$. J. Agric. Food Chem. 60:836-843.

Marks, L. R., E. A. Clementi, and A. P. Hakansson. 2012. The human milk protein-lipid complex HAMLET sensitizes bacterial pathogens to traditional antimicrobial agents. PLoS ONE 7:e43514.

Mathieu, C., and K. Badenhoop. 2005. Vitamin D and type 1 diabetes mellitus: State of the art. Trends endocrinol. Metab. 16:261-266.

Mossberg, A. K., Y. Hou, M. Svensson, B. Holmqvist, and C. Svanborg. 2010. HAMLET treatment delays bladder cancer development. J. Urol. 183:1590-1597.

Nielsen, S. B., K. Wilhelm, B. Vad, J. Schleucher, L. A. MorozovaRoche, and D. Otzen. 2010. The interaction of equine lysozyme:oleic acid complexes with lipid membranes suggests a cargo off-loading mechanism. J. Mol. Biol. 398:351-361.

Pedersen, J. N., J. S. Pedersen, and D. E. Otzen. 2015. The use of liprotides to stabilize and transport hydrophobic molecules. Biochemistry 54:4815-4823.

Permyakov, S. E., E. L. Knyazeva, L. M. Khasanova, R. S. Fadeev, A. P. Zhadan, H. Roche-Hakansson, A. P. Hakansson, V. S. Akatov, and E. A. Permyakov. 2012. Oleic acid is a key cytotoxic component of HAMLET-like complexes. Biol. Chem. 393:85-92.

Pols, H. A., J. C. Birkenhager, J. A. Foekens, and J. P. van Leeuwen. 1990. Vitamin D: A modulator of cell proliferation and differentiation. J. Steroid Biochem. Mol. Biol. 37:873-876.

Renken, S. A., and J. J. Warthesen. 1993. Vitamin D stability in milk. J. Food Sci. 58:552-555.

Rigby, W. F., S. Denome, and M. W. Fanger. 1987. Regulation of lymphokine production and human $\mathrm{T}$ lymphocyte activation by 1,25-dihydroxyvitamin D3. Specific inhibition at the level of messenger RNA. J. Clin. Invest. 79:1659-1664.
Ron, N., P. Zimet, J. Bargarum, and Y. D. Livney. 2010. Beta-lactoglobulin-polysaccharide complexes as nanovehicles for hydrophobic nutraceuticals in non-fat foods and clear beverages. Int. Dairy J. 20:686-693.

Schwamberger, A., B. De Roo, D. Jacob, L. Dillemans, L. Bruegemann. J. W. Seo, and J. P. Locquet. 2015. Combining SAXS and DLS for simultaneous measurements and time-resolved monitoring of nanoparticle synthesis. Nucl. Instrum. Meth. B 343:116-122.

Schwartz, G. G., M. H. Wang, M. Zang, R. K. Singh, and G. P. Siegal. 1997. 1 alpha,25-dihydroxyvitamin D (calcitriol) inhibits the invasiveness of human prostate cancer cells. Cancer Epidemiol. Biomarkers Prev. 6:727-732.

Semo, E., E. Kesselman, D. Danino, and Y. D. Livney. 2007. Casein micelle as a natural nano-capsular vehicle for nutraceuticals. Food Hydrocoll. 21:936-942.

Svensson, M., A. K. Mossberg, J. Pettersson, S. Linse, and C. Svanborg. 2003. Lipids as cofactors in protein folding: Stereo-specific lipid-protein interactions are required to form HAMLET (human alpha-lactalbumin made lethal to tumor cells). Protein Sci. 12:2805-2814

Tangpricha, V., P. Koutkia, S. M. Rieke, T. C. Chen, A. A. Perez, and M. F. Holick. 2003. Fortification of orange juice with vitamin D: A novel approach for enhancing vitamin D nutritional health. Am. J. Clin. Nutr. 77:1478-1483.

Wang, Q., J. C. Allen, and H. E. Swaisgood. 1997. Binding of vitamin D and cholesterol to beta-lactoglobulin. J. Dairy Sci. 80:1054-1059.

Webb, A. R., B. R. DeCosta, and M. F. Holick. 1989. Sunlight regulates the cutaneous production of vitamin D3 by causing its photodegradation. J. Clin. Endocrinol. Metab. 68:882-887.

White, J. H. 2008. Vitamin D signaling, infectious diseases, and regulation of innate immunity. Infect. Immun. 76:3837-3843.

Wilhelm, K., A. Darinskas, W. Noppe, E. Duchardt, K. H. Mok, V. Vukojevic, J. Schleucher, and L. A. Morozova-Roche. 2009. Protein oligomerization induced by oleic acid at the solid-liquid interfaceequine lysozyme cytotoxic complexes. FEBS J. 276:3975-3989. 